\title{
Severe Dyspnea and Cough
}

\author{
Traci Mellinger Kohl \\ Thomas Jefferson University \\ Elizabeth Cartwright \\ Thomas Jefferson University
}

Follow this and additional works at: https://jdc.jefferson.edu/tmf

Part of the Cardiology Commons

Let us know how access to this document benefits you

\section{Recommended Citation}

Mellinger Kohl, Traci and Cartwright, Elizabeth (2001) "Severe Dyspnea and Cough," The Medicine Forum: Vol. 3 , Article 6.

DOI: https://doi.org/10.29046/TMF.003.008

Available at: https://jdc.jefferson.edu/tmf/vol3/iss1/6

This Article is brought to you for free and open access by the Jefferson Digital Commons. The Jefferson Digital Commons is a service of Thomas Jefferson University's Center for Teaching and Learning (CTL). The Commons is a showcase for Jefferson books and journals, peer-reviewed scholarly publications, unique historical collections from the University archives, and teaching tools. The Jefferson Digital Commons allows researchers and interested readers anywhere in the world to learn about and keep up to date with Jefferson scholarship. This article has been accepted for inclusion in The Medicine Forum by an authorized administrator of the Jefferson Digital Commons. For more information, please contact: JeffersonDigitalCommons@jefferson.edu. 


\section{Severe Dyspnea and Cough}

Traci Mellinger Kohl, MD, Resident Department of Internal Medicine 1999-2002

Elizabeth Cartwright, MD, Resident Department of Internal Medicine 1999-2002

A 43 year-old white male with a history of hypertension and a smoking history of 30 pack-years presented to the emergency room complaining of cough, severe dyspnea, nausea, and vomiting. Ten days prior to presentation, he experienced flu-like symptoms with a low-grade fever, myalgias, and malaise that lasted approximately four days but resolved spontaneously. He had had a cough productive of white sputum and blood-tinged nasal drainage for one week. Three days prior to presentation, he began to experience right upper quadrant abdominal pain and bilious vomiting. The patient worked as a bar inspector and had a routine PPD check 9 months prior to presentation which was negative. However, his daughter did have a recent positive screening PPD with a negative chest $\mathrm{x}$-ray.

On presentation, his temperature was 99.8 degrees Fahrenheit, blood pressure was $180 / 96 \mathrm{~mm} / \mathrm{Hg}$, pulse was $117 \mathrm{bpm}$, and pulse oximetry was $92 \%$ on room air. He was admitted to Thomas Jefferson University Hospital. On the day following admission, the patient became more dyspnic and required increased levels of oxygen, necessitating transfer to the medical coronary intensive care unit. Exam at this time revealed the patient was in moderate respiratory distress with pulse oximetry of $95 \%$ on face mask of $50 \%$ oxygen, blood pressure of $195 / 105 \mathrm{~mm} / \mathrm{Hg}$, pulse of $125 \mathrm{bpm}$, and respiratory rate of 36. Lung exam revealed scattered rales worse on the right but no wheezing. On cardiac exam, he was tachycardic but no murmurs, rubs, or gallops were heard. Abdominal exam revealed normal bowel sounds, no masses or distention, and no tenderness. The skin exam revealed no rashes, and the neurologic exam was intact.

Laboratory studies revealed an elevated white blood cell count of $12,400 \mathrm{ml}^{3}$ with $87 \%$ neutrophils, $3 \%$ bands, $5 \%$ lymphocytes, and 5\% monocytes. The hemoglobin was slightly decreased at $12 \mathrm{~g} / \mathrm{dL}$ with an MCV of $96 \mathrm{fL}$. The platelet count was within normal limits. The patient had a decreased sodium of $118 \mathrm{mmol} / \mathrm{L}$, elevated potassium of $5.3 \mathrm{mmol} / \mathrm{L}$, decreased chloride of $87 \mathrm{mmol} / \mathrm{L}$, and decreased ionized calcium of $4.3 \mathrm{mg} / \mathrm{dL}$. His BUN was elevated at $39 \mathrm{mg} / \mathrm{dL}$ with an elevated creatinine of $1.3 \mathrm{mg} / \mathrm{dL}$. Liver function tests were within normal limits. Arterial blood gas obtained when dyspnea worsened revealed a $\mathrm{pH}$ of $7.43, \mathrm{pCO} 2$ of $38 \mathrm{mmHg}, \mathrm{pO} 2$ of 52
$\mathrm{mmHg}$, and oxygen saturation of $88 \%$ on room air. A repeat blood gas on a $50 \%$ facemask revealed a $\mathrm{pH}$ of 7.3 , pCO2 of $33 \mathrm{mmHg}$, and $\mathrm{pO} 2$ of $78 \mathrm{mmHg}$. Urinalysis revealed $1+$ ketones, $1+$ protein, and $4+$ blood. Chest x-ray showed bilateral interstitial infiltrates and an echocardiogram was normal with ejection fraction of $65 \%$ except for mild concentric LVH.

The patient developed a single episode of hemoptysis with blood-tinged sputum, worsening shortness of breath, and respiratory fatigue two days after transfer to the intensive care unit. At this time the patient underwent elective intubation. Also of note was that his creatinine had increased from 1.2 on admission to $3.1 \mathrm{mg} / \mathrm{dL}$ on the day of intubation. Studies for influenza titers, urine legionella antigen, HSV, CMV, hepatitis B and C panels, cryoglobulin, pANCA, and cANCA were sent at that time, and later found all to be negative. Concern over his episode of hemoptysis and rise in creatinine prompted a workup for pulmonary-renal syndromes. Urine microscopic exam revealed red blood cell casts, and erythrocyte sedimentation rate was found to be elevated at $104 \mathrm{~mm} / \mathrm{hr}$. The patient was given the presumptive diagnosis of Goodpasture's Syndrome and was started on empiric plasmapheresis, cyclophosphamide, and steroids for the worsening renal and pulmonary function. His creatinine and oxygenation improved greatly with the treatment, and he was able to be extubated one day after initiation of therapy.

A renal biopsy with immunoflourescent staining was performed the day after starting therapy. This demonstrated linear staining of the glomerular basement membrane for IgG and complement, confirming the diagnosis of Goodpasture's Syndrome. The patient continued to recover and repeat chest $\mathrm{x}$-ray performed 9 days after initiation of therapy demonstrated marked improvement in his pulmonary disease. Interestingly, serum anti-GBM antibodies remained negative, however this test has only a $60 \%$ sensitivity.

\section{Discussion:}

Goodpasture's Syndrome is a relatively rare syndrome. The incidence is one case per 2 million in the Caucasian population. The peak incidence has a mean age of 35 , 
with a second peak in the 6 th or 7 th decades. Interestingly, men have a 6 times greater risk of developing Goodpasture's during their second or third decades of life, but by the second peak the chance is equal between men and women ${ }^{1}$. Risk factors include recent Influenza A infection, exposure to hydrocarbons (usually found in dry-cleaning solvents), smoking, and HLADRw15, HLA-DRw16, and HLA-DR $4^{1}$.

The disease occurs when the patient develops an antiglomerular basement membrane antibody (Anti-GBM), which is against the $\mathrm{C}$-terminus of the alpha- 3 chain of type IV collagen ${ }^{2}$. The alpha- 3 chain is only found in renal glomerular basement membranes and alveolar basement membranes, whereas all other basement membranes in the body express alpha-1 and alpha- 2 . Additionally, the glomerular basement membrane is at risk of attack due to direct contact with antibodies in the blood through fenestrae in the glomerular endothelium. The alveolar basement membrane becomes exposed to large molecules like IgG when there is increased permeability from non-specific lung injury (such as smoking, Influenza A, or hydrocarbon exposure). The antibody causes a Type II hypersensitivity reaction, causing homogenous diffuse linear deposition of IgG (and often $\mathrm{C} 3$ ) along the glomerular and alveolar basement membranes.

Most patients with Goodpasture's Syndrome have both pulmonary and renal disease. These comprise $60-80 \%$ of patients with anti-GBM disease. Twenty to $40 \%$ have renal disease alone, and 10\% have pulmonary hemorrhage alone ${ }^{3}$. The majority of patients have hemoptysis at some point, and it usually precedes renal disease by hours to months to years. In some cases, only bronchioalveolar lavage or biopsy can demonstrate the hemorrhage. Usually the initial pulmonary blood loss is small, however massive hemoptysis can result in rapid respiratory failure and death. Renal failure can occur rapidly, over hours to weeks, and is described as rapidly progressive glomerulonnephritis. Other symptoms are non-specific. Nausea and vomiting, such as in this patient, occurs in $41 \%$ of patients with Goodpasture's. Chills and fever are present in $25 \%$, chest pain in $40 \%$, and $14 \%$ have weight loss ${ }^{3}$.
Diagnosing Goodpasture's Syndrome is often a challenge initially, but the right constellation of signs, symptoms, and lab results will heighten suspicion. Patients with Goodpasture's will have a slightly elevated ESR, a fall in hemoglobin as well as iron deficiency anemia, rising creatinine with proteinuria, hematuria, and red blood cell casts on the urinalysis. A positive Anti-GBM antibody is usually diagnostic, however, it is a difficult test to utilize. One method of determining Anti-GBM is by using direct immunofluorescence, in which the patient's serum is incubated with normal renal tissue. However, this has a $40 \%$ false negative result rate, such as seen in our patient ${ }^{4}$. ELISA for Anti-GBM is the most sensitive and specific, however false positives can occur if the assay is done without utilizing purified Goodpasture antigen. Western Blot is not widely available. If testing is done appropriately and yields a true positive, there is a close correlation between antibody level and disease activity.

Renal biopsy is the definitive diagnostic procedure. Light microscopy in early Goodpasture's will show mesangial expansion and hypercellularity, middle stage will show focal segmental glomerulonephritis (GN), advanced shows crescentic GN with widespread glomerular necrosis ${ }^{1}$. Immunofluorescence targeting $\operatorname{IgG}$ or $\mathrm{C} 3$ will demonstrate a characteristic linear basement membrane distribution. Lung biopsy is of much lower yield. Light microscopy only shows non-specific alveolar hemorrhage, and immunofluorescence only occasionally shows linear staining of lung tissue.

Untreated, the clinical course is grave. The renal failure rapidly progresses from mild renal insufficiency to endstage, and oliguria is a poor prognosticator. However, it is the pulmonary hemorrhage which is the primary cause of death in these patients. Surprisingly, the amount of hemoptysis does not correlate to degree of alveolar hemorrhage. Successful treatment will usually leave no residual pulmonary deficit or fibrosis.

Treatment goals encompass two arms; firstly, remove currently circulating antibodies (done through daily plasmapheresis for 2 weeks), and secondly, prevent further production of antibodies (utilizing immunosuppressives, such as cyclophosphamide and steroids for 6 months). The objective is to initiate treatment as soon as there is 
reasonable suspicion of Goodpasture's, and before endstage damage occurs. Anti-GBM antibody tests and biopsy results will take too long to become available, and the serum antibody may have a false negative. Even aggressive treatment usually does not improve severe renal failure, and with a creatinine $>6 \mathrm{mg} / \mathrm{dL}$ and no pulmonary involvement, treatment risks outweigh the benefits. Recurrence is rare if the patient is adequately treated for 6 months.

\section{References}

1. Kluth D, Rees A. Anti-Glomerular Basement Membrane Disease. J Am Soc Nephrol. 10: 2446-2453, 1999.

2. Kalluri R. Goodpasture's Syndrome. Kidney International. 55(3): 1120-1122, 1999.

3. Ball J, Young KR. Pulmonary Manefestarions opf Goodpasture's Syndrome: Antiglomoerular Basement Membrane Disease and Related Disorders. Clinics in Chest Medicine. 19 (4):777-791, 1998.

4. Pauker S, Kopelman R. Treating Before Knowing. NEJM. 327(19):1366-1369, 1992.

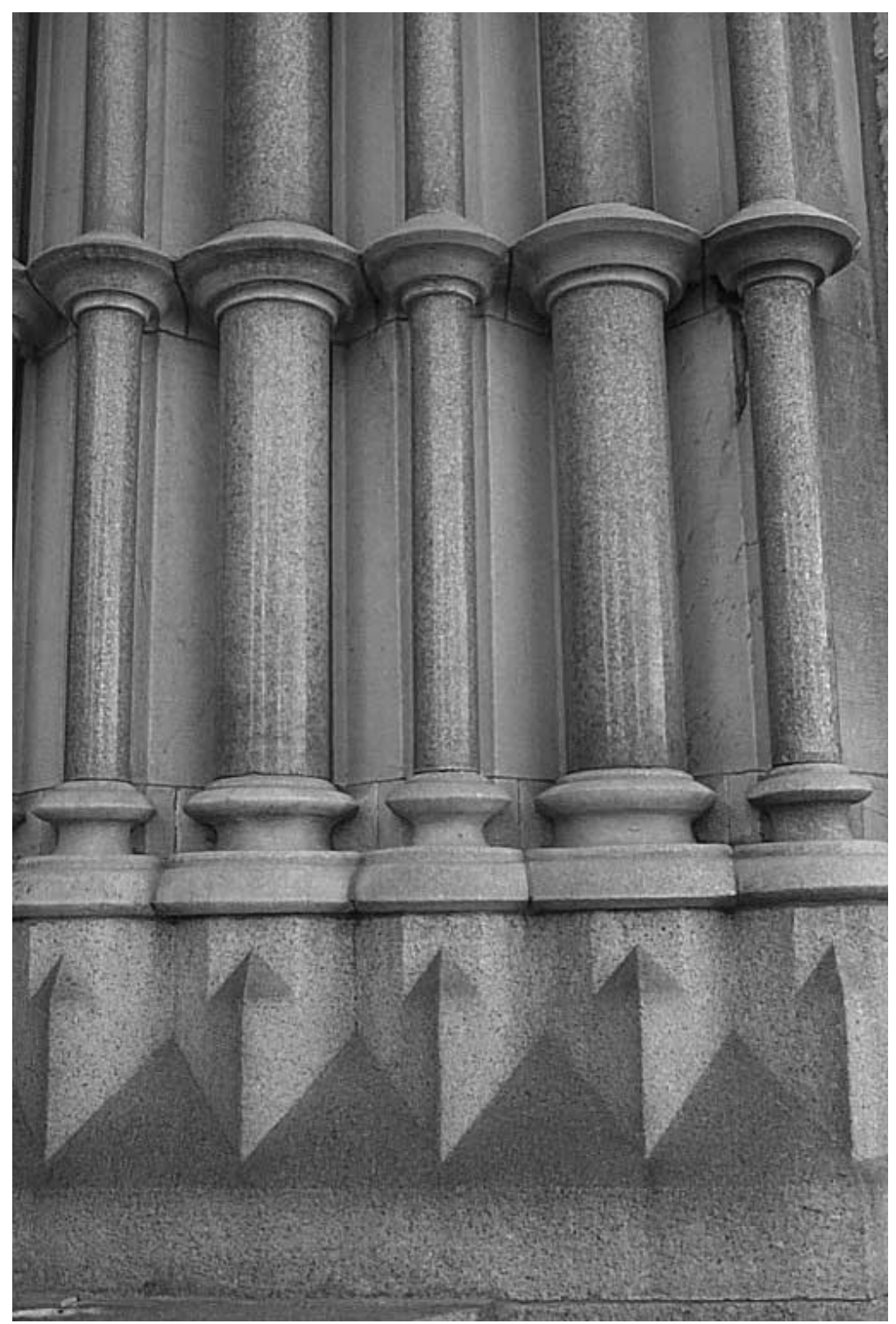

Photo by Thoai Tran, MD 